\title{
Increased incidence of spontaneous abortion and infertility in women with scleroderma before disease onset: a controlled study
}

\author{
ALAN J SILMAN'AND CAROL BLACK \\ From the 'Department of Clinical Epidemiology, The London Hospital; and the 'Department of \\ Rheumatology, West Middlesex Hospital
}

SUMMARY A postal questionnaire was used in a nationwide case control study of women with scleroderma to investigate whether there was an increased rate of spontaneous abortion before the onset of the disease. The results from 155 case control pairs studied showed that the women with scleroderma had twice the rate of spontaneous abortion and three times the rate of fertility problems (no successful pregnancy by the age of 35) of the control women. Previous uncontrolled studies have suggested that established scleroderma is associated with an adverse reproductive history. The results from this investigation suggest that the adverse reproductive history may antedate the clinical diagnosis of scleroderma by many years and may possibly have an aetiological role. Such a hypothesis is consistent with the, as yet unexplained, marked female excess in incidence of the disease, with the peak age of onset occurring shortly after the reproductive period.

Scleroderma (systemic sclerosis) is a disease of unknown aetiology with a marked, and as yet unexplained, female excess incidence. ${ }^{\prime}$ This excess is at its highest at 15:1 during the reproductive years, $15-45$. $^{2}$ Uncontrolled case series have recorded that the disease may develop during pregnancy, ${ }^{34}$ but whether this represents the chance simultaneous occurrence of the two events is unclear. Similarly, pregnancies in women with established scleroderma seem to be at increased risk of resulting in spontaneous abortion. ${ }^{34} \mathrm{~A}$ recent case control study did show an increased incidence of spontaneous abortion in women with scleroderma, but the authors were unable to distinguish whether the rate was higher before disease onset. ${ }^{5}$ We therefore report the findings of a retrospective paired study to determine whether women destined to develop scleroderma have an increased incidence of spontaneous abortion.

\section{Subjects and methods}

Women with scleroderma were recruited from three sources: $(a)$ direct referrals from physicians with an

Accepted for publication 5 November 1987

Correspondence to Dr Alan J Silman. Department of Clinical Epidemiology. The London Hospital Medical College. Bone and Joint Rescarch Unit, 25-29 Ashficld Strect, London E1 1AD. interest in the disease, $(b)$ the membership of the Scleroderma Society, and (c) the scleroderma membership of the Raynaud's Association. Information was sought from the patient's hospital physician to confirm diagnosis and the type of scleroderma, and also to obtain an approximate date of onset. The women themselves were also asked to recall the date of first symptoms as accurately as possible. Where there was doubt the earliest stated date was used. Women with either localised scleroderma or mixed connective tissue disease were excluded as were those in whom the diagnosis was not confirmed by their hospital physician. Remaining cases were only included if the recalled age of first symptoms was after 35 and if the current age was under 70. The first criterion was introduced to restrict the study as far as possible to women who had completed their reproductive activity before disease onset. The second criterion was designed to exclude older women whose recall of past events might be impaired. In all, 154 women were eligible for inclusion. Each of the above (the cases) was asked to provide the names and addresses of three friends or neighbours who could be approached to act as a control. Eleven cases refused, and of the remainder, one control was selected at random from the three names provided and invited to participate in the study. This first 
selected control was excluded if they were related to the case or had scleroderma (or any other connective tissue disorder); and a second control was selected.

Agreement to participate was obtained from 115 of the 143 controls contacted. Each of the cases and controls was sent an indentical postal questionnaire covering details of oral contr.ceptive use, fertility history, and details of both successful and unsuccessful pregnancies. The questionnaire had previously been validated against probed interviews in outpatient attenders.

Only obstetric events before the age of 35 were considered for analysis. Infertility was defined ats the presence of both self reported difficulty in conception and the failure to achieve a successful pregnancy by the age of 35 . A matched paired analysis was undertaken comparing the incidence of events in the cases and their matched controls. Estimated relative risks for the obstetric events studied were derived from the ratios of the discordant pairs and the $95 \%$ confidence intervals (CIs) calculated."

\section{Results}

The case and control women were very similar in relation to their mean year of birth. marital status. and mean year of menarche (Table 1). There were also no differences between the 115 cases studied and the 39 women with scleroderma who did not provide a paired control.

The case and control women were also similar in their present or former use of oral contraceptives (Table 1), which on paired analysis showed 21 pairs where only the case had used oral contraceptives and 16 pairs with only the control (relative risk $1 \cdot 3$, $95 \%$ CI $(0 \cdot 7-2 \cdot 5)$.

Conversely, the spontaneous abortion rate was higher in the cases, with $33(28.7 \%)$ reporting at

Table 1 Baseline comparison of women with scleroderma and controls

\begin{tabular}{|c|c|c|c|}
\hline & $\begin{array}{l}\text { Women with } \\
\text { scleroderma } \\
(n=115)\end{array}$ & $\begin{array}{l}\text { Controls } \\
(n=115)\end{array}$ & $\begin{array}{l}\text { Women with } \\
\text { scleroderma } \\
\text { not providing } \\
\text { controls } \\
(n=39)\end{array}$ \\
\hline $\begin{array}{c}\text { Mean year of } \\
\text { birth (SE) }\end{array}$ & $1933(1.3)$ & $1933(1 \cdot 6)$ & $1931(2 \cdot 6)$ \\
\hline $\begin{array}{l}\text { Ever marricd } \\
\text { (No. } \%)\end{array}$ & 102.88 .7 & 104. 9()$\cdot 4$ & $36.92 \cdot 3$ \\
\hline $\begin{array}{l}\text { Mean age of } \\
\text { menarche (SE) }\end{array}$ & $12 \cdot 8(() \cdot 2)$ & $13 \cdot()(0 \cdot 2)$ & $12 \cdot 6(0 \cdot 4)$ \\
\hline $\begin{array}{l}\text { Ever used oral } \\
\text { contraceptive } \\
\text { (No. \%) }\end{array}$ & $36.31 \cdot 3$ & $31.27 \cdot 0$ & $11.28 \cdot 2$ \\
\hline
\end{tabular}

least one such event compared with 20 $(17 \cdot 4 \%)$ controls. Matched paired analysis showed (Table 2) that this was equivalent to a relative risk of $2 \cdot 1$. which was just significant $(p=0) \cdot(25)$. In addition. multiple abortions were more frequently reported in the women with scleroderma (Fig. 1). Thus the 33 women had had 49 abortions (mean 1.5 ) compared with 24 in the 20) controls (mean 1.2). None of the latter reported more than two abortions compared with three cases reporting three events and one reporting five.

Fertility problems, as defined above, were reported by 12 women. nine cases and three controls. This excess relative risk of three was not significant. Not surprisingly. however. when the numbers of women

Table 2 Concordance in scleroderma/control pairs for spontaneous abortion and other fertility problems

Ever had spontaneous abortion?

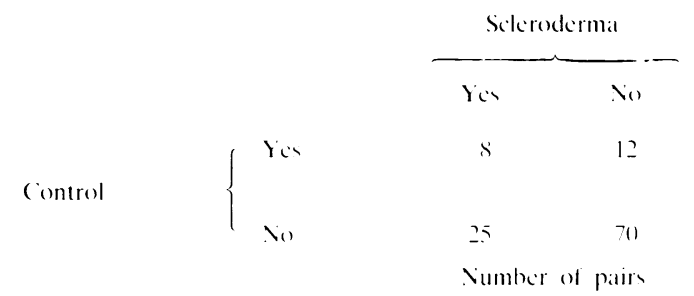

Relative risk $=2 \cdot 1$

95\%, Confidence interval $1 \cdot(1+\downarrow \cdot 3$

Fertility problem?

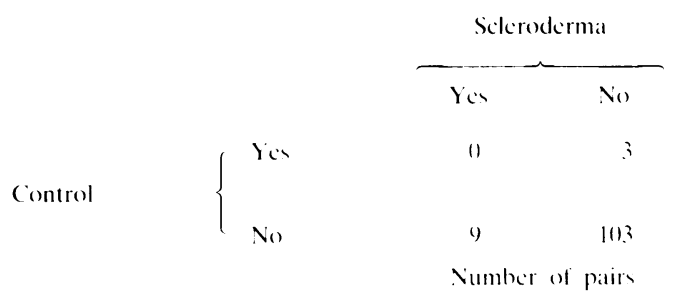

Relative risk $=3 \cdot(1)$

$95 \%$ Confidence interval $11.8-11.1$

Ever had spontaneous abortion or fertility problem, or hoth?

silerodermat

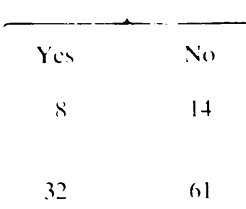

Number of pairs

Relative risk $=2 \cdot 3$

$95 \%$ Confidence interval $1 \cdot 2-4 \cdot 3$ 
$\%$

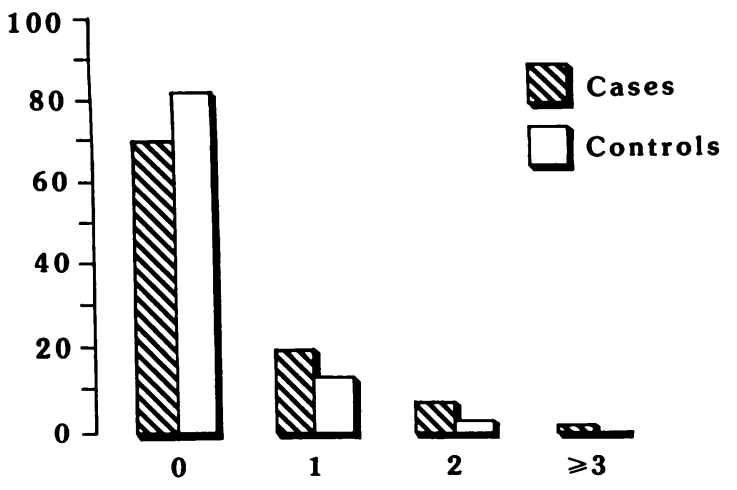

Number of Miscarriages

Fig. 1 Number of miscarriages in women with scleroderma and controls.

who had reported at least one abortion or had a fertility problem. or both. were combined it was shown that the presence of that combination was present in a significant excess in the cases (Table 2).

\section{Discussion}

Women with scleroderma in this investigation reported an increase in spontaneous abortions and fertility problems before the clinical onset of their disease, an observation not previously reported. There are a number of biases, however.

Firstly, the cases may selectively have a better recall for events in an attempt to explain their disease. This is difficult to disprove, but there was no reported excess in either oral contraceptive use or indeed in cigarette smoking in the cases, either of which might have been increased in the presence of this bias. In addition, recall of a spontaneous abortion in our pilot studies of the questionnaire was complete compared with interview.

Secondly, the cases, in part. selected their own controls, and thus the latter were not a random sample of the general population. Against this, however, the controls selected were similar to the cases in many respects (age, marital status) and it is likely that the similarity would have extended to other areas of life. Hence the effect of this bias would be to have minimised any difference between cases and controls, hence strengthening the results reported. A possible further bias is that, of the 154 women with scleroderma, information was only included on the 115 with data from a matched control. As Table 1 shows, however, the cases with and without controls were similar.
Thirdly, dating the onset of scleroderma is difficult. The delay between first symptoms, such as Raynaud's, and clinical diagnosis is frequently many years. The symptoms themselves often arise insidiously and thus the recalled dates used in this study are subject to error. The mean age of diagnosis in the women with scleroderma was, however, 48.7 years and thus at some distance from the obstetric events (before age 35). Despite this, the presence of early, asymptomatic disease, even over this duration, cannot be ruled out: the results from this study being consistent with the findings from women with established disease. It is impossible to distinguish in a retrospective study such as this, cause and effect.

Alternatively, the obstetric problems could be causally related to scleroderma, and the reported increased abortion rate with established disease, therefore, may not be a direct effect of the disease but rather reflect the increased tendency of these women to abortion. Further, although only a minority $(29 \%)$ of the women with scleroderma recalled such an event, we cannot rule out early and unrecognised pregnancy loss in some of the remainder. There is no biological link to support this hypothesis. Scleroderma has been postulated as a type of chronic graft versus host disease resulting from transplacental transfer of cells between mother and fetus (S Pereira, personal communication). Whether such a phenomenon is more likely to occur after blighted pregnancies is unknown.

Women with established scleroderma, as mentioned earlier, probably do have an excess of spontaneous abortions, but it is unlikely there are different mechanisms causing an increased abortion rate both before and after disease onset.

The data from this study provide one explanation of the previously unexplained female excess in scleroderma. It is of interest, therefore, that in the chronic scleroderma-like phase of the Spanish cooking oil syndrome there was an equal sex incidence in childhood but an eightfold female excess in adult life (A Arnaiz-Villena, personal communication).

Such an observation is consistent with disease risk being related to both a known environmental agent and a postpubertal factor in women. We postulate that the latter factor may relate to pregnancy experience in some women.

This study was financially supported by the Scleroderma Society. We also acknowledge the helpful cooperation of the Scleroderma Socicty and the Raynaud's Association Trust in providing access to their members with scleroderma. We are also grateful to our colleagues in the UK Scleroderma Study Group (Dr B M Ansell. Professor P A Bacon. Professor M I V Jayson. Dr P J Maddison) for notifying patients and for their support. 


\section{References}

1 Medsger T A. Masi A T. Epidemiological systemic sclerosis (scleroderma). Ann Intern Med 1971: 74: 71+21.

2 Michet C J. McKenna C H. Elveback L R. Kaslow R A. Kurland L T. Epidemiology of systemic lupus erythematosus and other connective tissue discases in Rochester Minnesota 1950) through 1979. Ma1\% (lin Proc 1985: 60: 105-13.
3 Johnson T R. Banner E A. Winkelmann R K. Scleroderma and pregnancy. Obstet Gynecol 1964: 23: 467-9.

4 Slate W G. Graham A R. Scleroderma and pregnancy. Am J Obstet Gynecol 1968: 101: 33.5-41.

5 Giordano M. Valentini G. Lupoli S. Pregnancy and systemic sclerosis. Arthritis Rheum 1985: 28: 237-8.

6 Schlesselman J J. Case control studies, design conduct analysis. New York: Oxford University Press. 1982. 